\title{
Examination of Relationships of Scores Obtained in Grades 10 and 12 with the Entry and Success in Undergraduate Medical Education
}

\author{
A P Gautam, ${ }^{1}$ BH Paudel, ${ }^{1}$ CS Agrawal, ${ }^{1}$ SR Niraula,,${ }^{1}$ J Van Dalen ${ }^{2}$
}

\author{
${ }^{1}$ B P Koirala Institute of Health Sciences, Dharan, \\ Nepal \\ ${ }^{2}$ Maastricht University, The Netherlands
}

\author{
Corresponding Author \\ Akshaya Prasad Gautam \\ Department of Health Professions Education \\ B P Koirala Institute of Health Sciences \\ Dharan, Nepal. \\ E-mail:akshayagautam@yahoo.com
}

Citation

A P Gautam, BH Paudel, CS Agrawal, SR Niraula, J Van Dalen. Examination of Relationships of Scores Obtained in Grades 10 and 12 with the Entry and Success in Undergraduate Medical Education. Kathmandu Univ med J 2012;37(1):66-71.

\author{
ABSTRACT \\ Background
}

Entrance examination (admission test) is the most important and widely accepted method of student selection for admission into medical schools in Nepal. For many schools it is the only criterion of student selection.

\section{Objectives}

To examine relationships of scores obtained in schooling (grade 10 and 12), medical entrance and MBBS professional examinations in a cohort to identify predictive strength for entry into medical school and success in medical education.

\begin{abstract}
Methods
Exam scores from grade 10 to medical entrance and professional exams of undergraduate medical education of a total of 118 medical students who entered medical school between 1994 and 1998 only through the merit of open competitive medical entrance examination at the BP Koirala Institute of Health Sciences (BPKIHS) were assessed.
\end{abstract}

\section{Results}

Student selection for admission in MBBS course at BPKIHS and their subsequent success were not determined by difference in outcomes of public \& private management of schools at grade 10 (selection $p=0.80 \&$ success $p=0.32$ ) and grade 12 (selection $p=0.59$ \& success $p=0.55$ ). Grade 12 averaged scores had no relationship in getting these students selected for admission into medical course $(r=0.08, p=0.37)$, but did show correlation with the overall success in medical education $(r=0.32, p=0.00)$. Scores in physics at grade 12 retained predictive strength in success in medical education $(r=0.19, p=0.04)$.

\section{Conclusion}

The present student selection criteria for medical education are not appropriate and need to incorporate other attributes of candidates along with cognitive aspects.

\section{KEY WORDS}

admission test, medical education, medical students, performance, predictions, selection criteria

\section{INTRODUCTION}

New student selection is one of the most important regular activities in all medical schools. Appropriate selection of medical students is a fundamental prerequisite if medical schools are to produce competent and caring doctors. Every school aims to select best students who can achieve all expected competencies in time, and show interest to serve the communities at risk. In Nepal entrance examination is the most important and widely accepted method of student selection for admission into medical schools. For many schools it is the only criterion of student selection. Candidates who are on top of the merit list drawn from the entrance examination are given admission. The B.P. Koirala Institute of Health Sciences (BPKIHS), a health science university established in 1994, also follows the same system. Candidates who have passed intermediate or twelve-grade in science (i.e., qualifying examination) are eligible to apply for the entrance examination. Selecting appropriate candidates for medical education is difficult both in privileged and under-privileged world. There is a 
Table 1.Mean values of scores obtained in school \& college examinations, and variance observed in public $\&$ private management

\begin{tabular}{|c|c|c|c|c|c|c|c|c|}
\hline \multirow[b]{2}{*}{ Performance (\%) } & \multicolumn{4}{|c|}{ School Types } & \multicolumn{4}{|c|}{ College Types } \\
\hline & $\begin{array}{l}\text { Public } \\
(n=88)\end{array}$ & $\begin{array}{l}\text { Private } \\
(n=88)\end{array}$ & $\mathbf{F}$ & $p$ value & $\begin{array}{l}\text { Public } \\
(n=44)\end{array}$ & $\begin{array}{l}\text { Private } \\
(n=74)\end{array}$ & $F$ & $p$ value \\
\hline School Performance & 69.98 & 73.25 & 4.42 & 0.04 & - & - & - & - \\
\hline College Performance & 69.80 & 72.34 & 2.31 & 0.13 & 67.43 & 74.23 & 24.45 & 0.00 \\
\hline Entrance Success & 63.08 & 63.69 & 0.06 & 0.80 & 64.27 & 63.09 & 0.30 & 0.59 \\
\hline MBBS Success & 67.78 & 68.75 & 1.01 & 0.32 & 68.18 & 68.69 & 0.35 & 0.55 \\
\hline
\end{tabular}

continuous search for appropriate factors (predictors) that are valid, reliable, cost-effective, and less time consuming. However, different countries/institutions use different criteria for selecting students in medical education. The most important thing is what criteria if applied can select best candidates as future doctors.

The main objective of this study was to examine any relationships of scores obtained in schooling (grade 10 \& 12), medical entrance and MBBS professional examinations in a cohort to identify predictive strength for entry into medical school and success in medical education.

\section{METHODS}

Permission to have access to the academic performance records of students admitted from 1994 to 1998 was obtained from the Institute authority. Institute maintains an individual record-file of each student admitted in every programme. Scores obtained by each student in $10^{\text {th }}$ Grade School Leaving Certificate Examination (SLC), two-year Intermediate of Science (I. Sc.) Examination, Entrance Examination for Medical School, and Annual Examination Records of the medical professional examination (MBBS) were entered into the computer using SPSS-10.

Performance records of all students admitted in to the medical course with the same selection criteria from 1994 to 1998 were analyzed. The percentage (\%) of scores of each level: SLC, I.Sc, Entrance Examination, first to final year professional examinations were computed with each other using multiple regression analysis. The independent variables were types of school (public and private) and scores in $12^{\text {th }}$ grade schools (college scores). The analysis was repeated after combination of scores to see the predictive strength of:

Grade 10 and college scores (Grade 12) to first year through final year MBBS examinations;

Public and private schools and colleges performances to entrance examination and to success in medical education;

Grade 10, college (Grade 12) and entrance examination scores to first year through final year MBBS examinations;

Chemistry, biology, physics and English scores in college level examinations to entrance examination.

The values are expressed in terms of means. The data was analyzed using ANOVA (for $F \& p$ ), correlation matrix
(Pearson's correlation) and regression analyses. A p value of $<0.05$ is considered statistically significant. The mean age of the sample at the time of entry into the medical school was 20 years with a standard deviation of 1.33 .

\section{RESULTS}

The mean scores of $10^{\text {th }}$ grade school examination in public schools (69.98\%) and private schools (73.25\%) were significant $(p=0.04)$, but the significance was not reflected in medical entrance examination according to their types of schooling $(p=0.80)$. However, the mean scores of students from public and private schooling in their college performances were comparable, and the difference was not significant $(p=0.13)$ (Table 1$)$.

Table 2. Mean and variance in academic performances for gender difference.

\begin{tabular}{|lllll|}
\hline & Performance (\%) & Mean & F & p value \\
\hline school & Male & 72.39 & 0.03 & 0.86 \\
& Female & 72.88 & & \\
College & Male & 71.34 & 3.35 & 0.07 \\
& Female & 76.59 & & \\
\hline Entrance & Male & 64.09 & 3.98 & 0.05 \\
& Female & 55.49 & & \\
MBBS & Male & 68.54 & 0.12 & 0.73 \\
aggregate & Female & 67.95 & & \\
\hline
\end{tabular}

Similarly, the mean score in college level examinations obtained by the students who studied in public colleges $(67.43 \%)$ was lower than that of students who studied in private colleges (74.23\%). The difference was statistically significant $(p=0.00$ for $F=24.45)$. Nevertheless, in entrance examination, the difference of mean scores of public college graduates $(64.27 \%)$ and private college graduates (63.09 $\%)$ were not significant $(p=0.59)$. Likewise, the difference of mean scores in overall medical education between public and private college graduates was not significant $(p=0.55)$ (Table 1). Table 2 shows mean scores secured by male and female students in various examinations and the variances explained due to the gender in various performances showing not significant in any examination except in entrance examination ( $p=0.048$; rounded to 0.05 ). Scores of school and college were correlated and the relationship was significant $(r=0.24 ; p=0.01)$. However, it did not show relationships between school performance and medical entrance examination $(r=0.06 ; p=0.49)$. Similarly, it also 
Table 3 Correlations matrix showing realtionships among scores in school, college examinations, entrance examinations and MBBS annual examinations.

\begin{tabular}{|c|c|c|c|c|c|c|}
\hline Aggregate \% & 1st MBBS Score & 2nd MBBS Score & 3rd MBBS Score & 4th MBBS Score & 5th MBBS Score & MBBS aggregate \% \\
\hline $\begin{array}{ll}\text { School \% } & r \\
& \text { Sig }\end{array}$ & $\begin{array}{l}.23(*) \\
.01\end{array}$ & $\begin{array}{l}.24(* *) \\
.01\end{array}$ & $\begin{array}{l}.10 \\
.26\end{array}$ & $\begin{array}{l}.17 \\
.07\end{array}$ & $\begin{array}{l}.18(*) \\
.05\end{array}$ & $\begin{array}{l}.23(*) \\
.01\end{array}$ \\
\hline $\begin{array}{ll}\text { College } \% & r \\
& \text { Sig }\end{array}$ & $\begin{array}{l}.28(* *) \\
.00\end{array}$ & $\begin{array}{l}.27(* *) \\
.00\end{array}$ & $\begin{array}{l}.26(* *) \\
.00\end{array}$ & $\begin{array}{l}.24(* *) \\
.01\end{array}$ & $\begin{array}{l}.26(* *) \\
.00\end{array}$ & $\begin{array}{l}.32(* *) \\
.00\end{array}$ \\
\hline $\begin{array}{ll}\text { Entrance } \% & r \\
& \text { Sig }\end{array}$ & $\begin{array}{l}.39(* *) \\
.00\end{array}$ & $\begin{array}{l}.42(* *) \\
.00\end{array}$ & $\begin{array}{l}.42(* *) \\
.00\end{array}$ & $\begin{array}{l}.44(* *) \\
.00\end{array}$ & $\begin{array}{l}.01 \\
.94\end{array}$ & $\begin{array}{l}.41(* *) \\
.00\end{array}$ \\
\hline
\end{tabular}

$\mathrm{N}=118$

** Correlation is significant at the 0.01 level (2-tailed).

* correlation is significant at the 0.05 level (2-tailed).

Table 4. Correlation matrix showing relationships among scores in college examinations(subject wise, entrance examination and MBBS annual examinations.

\begin{tabular}{|c|c|c|c|c|c|c|c|c|c|}
\hline \multicolumn{2}{|c|}{ Scores in College } & \multirow{2}{*}{$\begin{array}{l}\text { Entrance \% } \\
\qquad .19\left(8^{*}\right)\end{array}$} & \multirow{2}{*}{$\begin{array}{l}\text { 1st MBBS } \\
\text { Score } \\
\qquad .21\left(^{*}\right)\end{array}$} & \multirow{2}{*}{$\begin{array}{l}\text { 2st MBBS Score } \\
\qquad .22\left(^{*}\right)\end{array}$} & \multirow{2}{*}{$\begin{array}{r}\text { 3rd MBBS Score } \\
\qquad .21\left(^{*}\right)\end{array}$} & \multirow{2}{*}{$\begin{array}{l}\text { 4th MBBS } \\
\text { Score } \\
\qquad 20\left(^{*}\right)\end{array}$} & \multirow{2}{*}{$\begin{array}{l}\text { 5th MBBS Score } \\
\qquad .21\left(^{*}\right)\end{array}$} & \multirow{2}{*}{$\begin{array}{l}\text { MBBS } \\
\%\end{array}$} & \multirow{2}{*}{$\begin{array}{r}\text { aggregate } \\
.25\left(^{* *}\right)\end{array}$} \\
\hline Physics & $r$ & & & & & & & & \\
\hline & Sig & .04 & .02 & .02 & .02 & .03 & .02 & & .01 \\
\hline \multirow[t]{2}{*}{ Biology } & $r$ & .03 & $.26(* *)$ & $.23(*)$ & $.27(* *)$ & $.20(*)$ & $.29(* *)$ & & $.30(* *)$ \\
\hline & Sig & .77 & .05 & .01 & .01 & .03 & .00 & & .00 \\
\hline \multirow[t]{2}{*}{ Chemistry } & $r$ & .15 & $.33(* *)$ & $.33(* *)$ & $.24(* *)$ & $.29(* *)$ & $.25(* *)$ & & $.35(* *)$ \\
\hline & Sig & .10 & .00 & .00 & .01 & .00 & .01 & & .00 \\
\hline \multirow[t]{2}{*}{ English } & $r$ & -.11 & .10 & .09 & .11 & .08 & .09 & & .11 \\
\hline & Sig & .23 & .28 & .349 & .25 & .37 & .35 & & .22 \\
\hline College & $r$ & .08 & $.28\left(^{* *}\right)$ & $.27(* *)$ & $.26(* *)$ & $.24(* *)$ & $.26(* *)$ & & $.32(* *)$ \\
\hline Aggregate \% & Sig & .37 & .00 & .00 & .00 & .00 & .01 & & .00 \\
\hline
\end{tabular}

** Correlation is significant at the 0.01 level (2-tailed).

* correlation is significant at the 0.05 level (2-tailed).

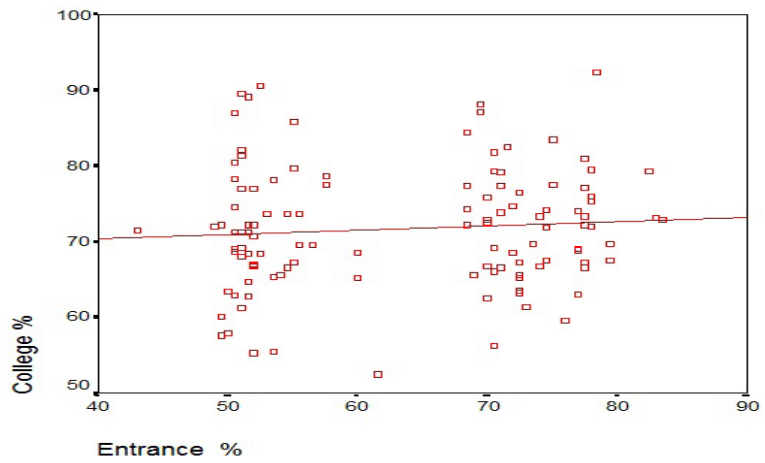

Figure 1. A scatter diagram with a Fit line showing poor relationship of Performances in college and.

showed that college scores had no effect in medical entrance examination ( $r=0.08 ; p=0.37$ ). However, correlation of college scores and performance in each year of medical education was significant at 0.01 level, 2 -tailed, $\left(1^{\text {st }}\right.$ year: $r=$ $0.28, P=0.00 ; 2^{\text {nd }}$ year: $r=0.27, P=0.00 ; 3^{\text {rd }}$ year: $r=0.26, P=$ $0.00 ; 4^{\text {th }}$ year: $r=0.24, P=0.01 ; 5^{\text {th }}$ year: $r=0.26, P=0.00$; and overall MBBS: $r=0.32, p=0.00$ ) (Table 3 ). There was hardly any significant relationship between college scores and scores in MBBS entrance examination. However, there was a positive relationship between college performance and MBBS performances (Figure 2). College scores in physics, chemistry and biology were found significant predictors of success in all professional examinations of MBBS. Among the science subjects in college level examinations physics claimed to have relatively more predictive strength ( $r=$

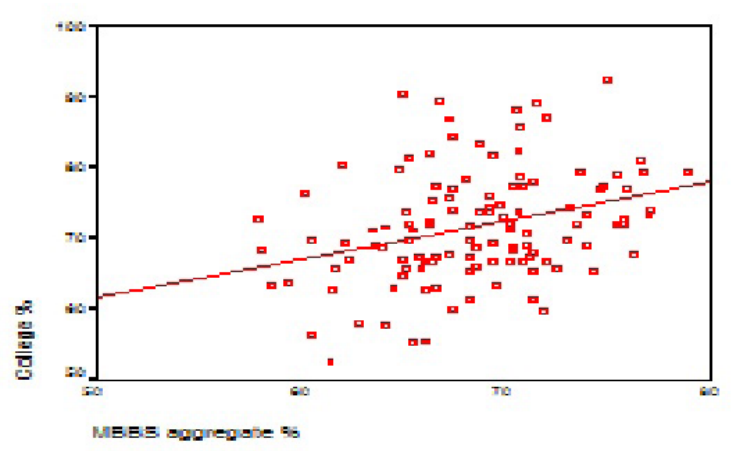

Figure 2.A scatter diagram with a fit line showing strong relationship of performancesin college and overall MBBS Examinations.

$0.19, p=0.04$ ) for getting admission into MBBS through the existing entrance examination (Table 4). Scores in biology, chemistry and English in college level examination did not show any predictive strength over medical entrance examination. However, there were positive relationships of scores in physics, chemistry and biology in college (I.Sc. or 10+2) level examination and scores in professional MBBS examinations from first year to fifth (final) year. However, none of the correlations between college scores and scores in MBBS annual examinations exceeded 0.35. In this relationship matrix, score in chemistry showed relatively stronger and significant relationship with the MBBS professional examinations compared with other science subjects. The correlation was significant $\left(1^{\text {st }}\right.$ year: $r=0.33, p=0.00 ; 2^{\text {nd }}$ year: $r=0.33, p=0.00 ; 3^{\text {rd }}$ year: $r=$ 
$0.24, p=0.01 ; 4^{\text {th }}$ year: $r=0.29, p=0.00$; and $5^{\text {th }}$ year: $r=$ $0.25, p=0.01$; and overall MBBS aggregate score: $r=0.35$, $p=0.00$ ) at the 0.01 level (2-tailed) (Table 4). Results of a stepwise regression analysis to predict factors for overall MBBS performances as output variables within the various levels of examinations (school, college, and entrance exam) showed that a model combining of school, college and entrance scores explained $27 \%$ of the variation with $\mathrm{F}=14.07$ and $\mathrm{p}=0.00$. The predictive value of $\mathrm{I} . \mathrm{Sc}$ or $10+2$ (college level) examination scores therefore accounted for only $10 \%$ of the variance in subsequent MBBS professional examinations. A backward regression analysis to examine the predictive strength of scores in physics, chemistry and biology in qualifying examination for predicting overall MBBS performances revealed that subjects in combination of chemistry and biology explained $14 \%$ of variance ( $F=$ 9.06, $p=0.00)$; and chemistry as strongest of all, explained $12 \%$ of variance $(F=16.41, p=0.00)$.

\section{DISCUSSION}

Some researchers have found relationship of some or other factors of selection criteria (cognitive or noncognitive) with scores of professional examinations. For example, Sandow et al have found that the undergraduate science grade point average and the score of perceptual motor aptitude test (PMAT) are the indicators of programmatic progress in the multivariate analysis. ${ }^{1}$ Mawhinney advocates the usefulness of $O$ and $A$ level examination results as predictors of a student's ability to pass pre-clinical examinations in anatomy, physiology and biochemistry. ${ }^{2}$ Some researchers found mixed predictive ability of school and higher secondary school performance for academic performance in medical education. Baig reports that when the scores of HSC (Higher Secondary Certificate) were combined with the IBA (Admission Test) scores, the predictive ability increases for first $(p=0.031)$, second $(p=0.032)$ and third year $(p=0.011)$ professional academic performance of medical students. ${ }^{3}$ He remarks that the SSC (Secondary School Certificate) had no effect on the academic performance of medical students. He concludes that IBA scores combined with HSC marks can predict academic achievement of medical students for the first three to four years, however, does not predict the performance in the final year, which is where the exit competencies are acquired by the graduates necessary for practicing medicine. The admission criteria lack the testing of non-cognitive attributes and learning abilities necessary for a medical graduate to practice skillfully. Hence a valid instrument for testing the positive attributes, which could predict good performance of medical doctors, should be designed. The study done by el Mouzan shows that performance on the admission test was a better predictor than high school grades in the first two levels of the medical curriculum. ${ }^{4}$ However, performance in a combination of certain high school and admission test subjects was a more powerful predictor of students' achievement at all levels. His study indicates that the college admission test is a useful additional tool in the process of medical student selection at his college. Likewise, Lumb \& Vail in a retrospective cohort study in predicting performance in the first three years of a medicine course with Year three objective structured clinical examination (OSCE) as a main outcome measure report that school-leaving grades were significant predictors of success in the OSCE. ${ }^{5}$ They also report that socioeconomic status and type of school attended were not found to affect performance on the course. There are some studies focused to finding out the predictive roles of premedical variables to a medical degree. Ferguson et al found in a study that information in the teacher's reference did not consistently predict performance. ${ }^{6}$ Information in the personal statement was predictive of clinical aspects of training, whereas A-level grades primarily predicted preclinical performance. The personality domain of conscientiousness was consistently the predictor across the course. They conclude that personality factors, in particular conscientiousness, need to be considered and integrated into selection procedures. Some researchers have suggested that variables chosen from the assessment domains of high school performance, written entrance examination, admission interview, and personality traits may be significant predictors of academic success during the first three years of medical study (Hoschl \& Kozeny). ${ }^{7}$ Similarly, the study done by Lipton et al suggests that incorporation of personality measurement with school academic achievement could be of value in selection procedures for applicants for medical school. ${ }^{8}$

However, there are studies that did not find significant relationship between the admission test scores and the scores obtained in the professional examinations. De Silva et al found that the marks of entrance examination, the one and only measure of academic performance used for selection of students admitted to University of Kelaniya, Sri Lanka is a very weak predictor of success in a medical school. ${ }^{9}$ Similarly, Neame et al found no significant correlations between outcome and levels of prior academic achievement, and their study did not support selection of medical students in University of Newcastle Medical School only from recent school-leavers who have studied science. ${ }^{10}$ Colins did not find relationship between academic achievement as reflected by marks in a national examination and scores in the panel interview, the group exercise, or the school principal's report. ${ }^{11}$ However, they found significant inter-correlations between the panel interview, group exercise and school report.

BPKIHS also heavily depends on cognitive domain performances (e.g., entrance exam percentage of physics, chemistry, biology, English and general knowledge). An empirical study to evaluate the predictors of professional performance in this institute remained important. This study is one-step forward in this direction.

Though private school students secured more marks their schooling and scores obtained are not supporting these 
students to get admitted into MBBS course at BPKIHS (Table 1). In the total study population the difference of scores in entrance examination according to the schooling (public stream and private stream) is insignificant $(p=.80)$. So this fact helps to establish that public private schooling has no influence on entrance examination of BPKIHS for admission into MBBS.

The difference of scores of private and public college graduates is significant ( $p=0.00$; Table 1$)$. However, this difference in scores has no impact on success in the medical entrance examination $(p=0.59)$. Private college graduates have even slightly lower performance in the medical entrance. The narrow differences in the mean scores in all professional MBBS examinations obtained by the private and public college graduates proves that college set-ups or types as private and public and the difference of scores in their graduates are not related to the performance in medical education. In this study the difference in overall MBBS scores between these two streams is insignificant $(p=0.55)$.

A significant correlation $(r=0.24, p=0.01)$ proves that high scorer in schools also obtain high score in college level examinations. However, this relationship does not exert any strength on success in medical entrance examination. But, good scorers in school are likely to get good scores in overall MBBS $(r=0.23, p=0.01)$. Very weak and insignificant relationship $(r=0.08, p=0.37)$ between college scores and medical entrance scores proves that higher scorers in college level education (i.e., I. Sc. Or 10+2 or A-level) are not necessarily get selected for admission through the present system of medical entrance examination. With these facts, one can make conclusive remarks that the process of selecting students for studying medical education was not appropriate and need to incorporate other attributes of the eligible candidates along with the cognitive aspects. Studies have shown that personality factors, in particular conscientiousness, would be the best predictor across the course. 6 The Edinburgh Declaration has also suggested to "employ selection methods for medical students which go beyond intellectual ability and academic achievement, to include evaluation of personal qualities" as one of the improvements to be made within the medical school itself for producing doctors who will promote the health of all people. $^{12}$

On the other hand, higher scorers in the college examinations have higher chances of success in all MBBS professional examinations $(r=0.32, p=0.00)$. Results of a stepwise regression analysis show that a model combining of school, college and entrance scores (model 3), explains $27 \%$ of the variation with $F=14.07$ and $p=0.00$. In a similar study done by Ferguson et al, they have found that the previous academic performance accounted for $23 \%$ of the variance in performance in undergraduate medical training. ${ }^{13}$ Looking into subject-wise scores in college examination and their relationships with the success in medical entrance, none of the subjects except physics showed significant correlation. The only significant predictor of success in the medical entrance examination was physics in college with correlation coefficient of $0.19(p=0.04)$. The data show that there are positive correlations of scores in physics, biology and chemistry in college level examination and scores of MBBS professional examinations (Correlation Matrix in Table 4). This match with the education component of the MBBS course which is mostly science based, claims students willing to undergo medical education should come from science background.

Performance of chemistry in college has dominant role in the success of medical education ( $r=0.35, p=0.00)$. The proportion of variance of chemistry score (in college examination) in the dependent variable (i.e., aggregate score of all MBBS professional examinations) explained by the regression model, that is $12 \%$, where as this figure in combination of all physics, biology and chemistry is 14 $\%$. However, the high residual sum of squares indicates that the model does not explain a lot of the variation in the dependent variable, and therefore needs to look for additional factors accountable for the higher proportion of the variation in the output variable. Cross validation using this estimated regression weight to predict similar outputs in different set of data would be suggestive. Scores in English did not show any significant correlation with scores in any MBBS professional examinations.

An attempt was made to see whether there were any gender relationships in scoring in various examinations. A very weak relationship only in medical entrance examination was observed; male performing better $(p=$ 0.048 ; rounded to 0.05 ). However, this weak relationship could not be expressed loudly because the number of female population in study was very small (i.e., 8). Some researchers have found results in their studies that females perform better in medical courses. ${ }^{4,14,15}$

Students scoring less than $50 \%$ (in aggregate of physics, chemistry, biology and English) were by default excluded from the study as the eligibility criteria do not allow them to apply for. Given a chance to study MBBS, possibility of doing better by them is unanswered. Scoring system in public and private schools might be different. Sample size, especially female population is low; therefore, generality of some of the findings is poor. However, they provide some indications for future studies with an adequate sample size.

\section{CONCLUSION}

We conclude that there is no influence of public and private schools in the selection of students for admission in MBBS course at BPKIHS and in their subsequent success in medical education. What matters is students' better performance in physics for being selected through the existing admission-test system and better performance in chemistry for future success in medical course at BPKIHS. However, a need of cross validation of the findings is very 


\section{important.}

The data indicate that the performances in I.Sc or $10+2$ examination and entrance examination do not fully support success in the community-based and innovative medical education of the BPKIHS. The present student selection criteria for admission into medical education at this institute therefore, need to incorporate other noncognitive attributes of candidates along with cognitive aspects.

\section{REFERENCES}

1. Sandow PL, Jones AC, Peek CW, Courts FJ, Watson RE. Correlation of admission criteria with dental school performance and attrition. $J$ Dent Edu 2002; 66(3):385-92.

2. Mawhinney BS. The value of ordinary and advanced level British school-leaving examination results in predicting medical students' academic performance. Med Educ 1976;10:87-9.

3. Baig LA. Predictive validity of the medical college admission criteria for academic performance: results from the four MBBS batches of Karachi Medical and Dental College. J Pak Med Assoc 2001 Sep;51(9):312-6.

4. El Mouzan MI. Secondary school and admission test grades as predictors of performance of medical students Med Educ 1992 Mar;26(2):123-7.

5. Lumb AB, Vail A. Comparison of academic, application form and social factors in predicting early performance on the medical course. Med Educ 2004 Sep;38(9):1002-5.

6. Ferguson E, James D, O'Hehir F, Sanders A. Pilot Study of the roles of personality, references, and personal statements in relation to performance over the five years of a medical degree. BMJ 2003 February 22; 326(7386): 429-432.

7. Hoschl C, Kozeny J. Predicting academic performances of medical students: the first three years. Am J Psychiatry 1997 Jun;154(6 Suppl):87-92.

8. Lipton A, Huxham GJ, Hamilton D. Predictors of success in a cohort of medical students. Med Educ 1984;18:203-10.

9. De Silva NR, Pathmeswaran A, De Silva HJ. Selection of students for admission to a medical school in Sri Lanka. Ceylon Med J 2004 Sep;49 (3):81-5.

10. Neame RL, Powis DA, Bristow T. Should medical students be selected only from recent school-leavers who have studied science? Med Educ $1992 ; 26(6): 433-40$.

11. Collins JP, White GR, Kennedy JA. Entry to medical school: an audit of traditional selection requirements. Med Educ 1995 Jan;29(1):22-8.

12. Edinburgh Declaration. World Conference on Medical Education of the World Federation of Medical Education; 12 August 1988; The City of Edinburgh, Scottish Development Agency.

13. Ferguson E, James D, Madeley L. Factors associated with success in medical school: systematic review of the literature. BMJ 2002 April 20; 324(7343): 952-957.

14. James, D.; Chilvers, C. Academic and non-academic predictors of success on the Nottingham undergraduate medical course 19701995. Med Educ 2001 Nov;35(11):1056-64.

15. Groves M, O'Rourke P, Alexander $H$. The association between student characteristics and the development of clinical reasoning in a graduate-entry, PBL medical programme. Med Teach 2003 Nov;25(6):626-31. 